\title{
IDENTIFICATION AND MANAGEMENT OF ALCOHOL WITHDRAWAL SYNDROME
}

\author{
Antonio Mirijello ${ }^{1}$, Cristina D’Angelo ${ }^{1}$, Anna Ferrulli ${ }^{1}$, Gabriele Vassallo ${ }^{1}$, Mariangela \\ Antonelli ${ }^{1}$, Fabio Caputo ${ }^{2,3}$, Lorenzo Leggio ${ }^{4,5,6}$, Antonio Gasbarrini ${ }^{1}$, and Giovanni \\ Addolorato $^{1}$ \\ ${ }^{1}$ Alcohol Use Disorders Unit, Department of Internal Medicine, Gemelli Hospital, Catholic \\ University of Rome, Rome, Italy \\ ${ }^{2}$ Department of Internal Medicine, SS Annunziata Hospital, Cento, Ferrara, Italy \\ ${ }^{3}$ Department of Clinical Medicine, "G. Fontana" Centre for the Study and Multidisciplinary \\ Treatment of Alcohol Addiction, University of Bologna, Bologna, Italy
}

${ }^{4}$ Section on Clinical Psychoneuroendocrinology and Neuropsychopharmacology, Laboratory of Clinical and Translational Studies, National Institute on Alcohol Abuse and Alcoholism, National Institutes of Health, Bethesda, MD, USA

${ }^{5}$ Intramural Research Program, National Institute on Drug Abuse, National Institutes of Health, Baltimore, MD, USA

${ }^{6}$ Center for Alcohol and Addiction Studies, Department of Behavioral and Social Sciences, Brown University, Providence, RI, USA

\section{Abstract}

Symptoms of alcohol withdrawal syndrome may develop within 6-24 hours after the abrupt discontinuation or decrease of alcohol consumption. Symptoms can vary from autonomic hyperactivity and agitation to delirium tremens.

The gold-standard treatment for alcohol withdrawal syndrome is represented by benzodiazepines. Among them, different agents (i.e., long-acting or short-acting) and different regimens (frontloading, fixed dose or symptom-triggered) may be chosen on the basis of patient characteristics. Severe withdrawal could require ICU admission and the use of barbiturates or propofol. Other drugs, such as alpha 2 -agonists (clonidine and dexmetedomidine) and beta-blockers can be used as adjunctive treatments to control neuroautonomic hyperactivity. Furthermore, neuroleptics can help control hallucinations. Finally, other medications for the treatment for alcohol withdrawal syndrome have been investigated with promising results. These include carbamazepine, valproate,

Please send any correspondence to: Giovanni Addolorato, M.D., Institute of Internal Medicine, Catholic University of Rome, Gemelli Hospital, Largo Gemelli 8, 00168 Rome, Italy, Phone: + 39-06-301556504334; Fax: + 39-06-35502775, g.addolorato@ rm.unicatt.it.

\section{Conflicts of Interest}

Dr. Addolorato served as a consultant for Ortho-McNeil Janssen Scientific Affairs, LLC, and D\&A Pharma, was paid for his consulting services and received lecture fees and grants from D\&A Pharma, CT Laboratories and Lundbeck.

Dr. Caputo reports personal fees from D\&A Pharma and personal fees from CT Pharmaceutical Industries.

Dr. Mirijello, Dr. D’Angelo, Dr. Ferrulli, Dr. Vassallo, Dr. Antonelli, Dr. Leggio and Dr. Gasbarrini report no financial interests or potential conflicts of interest. 
sodium oxybate, baclofen, gabapentin, and topiramate. The usefulness of these agents will be discussed in the text.

\section{Introduction}

Alcohol use disorder (AUD) was estimated to affect approximately $18 \%$ of the general population lifetime and 5\% annually [1]. Moreover, it has been estimated that almost $20 \%$ of adult patients in the emergency rooms suffer from AUD [2] and that the incidence of alcohol withdrawal syndrome (AWS) in patients admitted to surgical Intensive Care Unit (ICU) varies from 8 to $40 \%$, and seems to be associated with infectious complications and a higher mortality rate [3].

Up to $50 \%$ of AUD patients experience withdrawal symptoms $[4,5]$, a minority of whom requires medical treatment.

AWS represents a clinical condition characterized by symptoms of autonomic hyperactivity such as agitation, tremors, irritability, anxiety, hyperreflexia, confusion, hypertension, tachycardia, fever and diaphoresis. AWS usually develops in alcohol-dependent patients within 6-24 hours after the abrupt discontinuation or decrease of alcohol consumption. It is a potentially life-threatening condition whose severity ranges from mild/moderate forms characterized by tremors, nausea, anxiety, and depression, to severe forms characterized by hallucinations, seizures, delirium tremens and coma [6].

The mild-moderate form of AWS is often self-managed by patients or disappears within 2-7 days from the last drink [5, 7], while the more severe AWS requires medical treatment [4, 5]. The identification and subsequent treatment of AWS is of paramount clinical importance, given that AWS is one of the causes of preventable morbidity and mortality [8].

The goal of this "Therapy in Practice" paper is to provide a practical tool for the identification and management of AWS, with a focus on pharmacotherapy.

\section{Pathophysiology}

Gamma-aminobutyric acid (GABA) represents the main inhibitory neurotransmitter in central nervous system (CNS) while glutamate represents the main excitatory neurotransmitter.

Acute alcohol ingestion produces CNS depression secondary to an enhanced GABAergic neurotransmission [9] and to a reduced glutamatergic activity. The stimulation of $\mathrm{GABA}_{\mathrm{A}}$ receptors [10] and the inhibition of N-methyl-D-aspartate (NMDA) receptors [10, 11] represents the most known mechanisms.

Chronic CNS exposure to alcohol produces adaptive changes in several neurotransmitter systems, including GABA, glutamate and norepinephrine pathways [12] in order to compensate for alcohol-induced destabilization and restore a neurochemical equilibrium [13]. This adaptive phenomenon results in long-term reductions in the effects of alcohol in the CNS, i.e., tolerance $[10,14,15]$. In particular, changes observed after chronic alcohol 
exposure include a reduction in number, function, and sensitivity to GABA of the $\mathrm{GABA}_{\mathrm{A}}$ receptors (down-regulation) $[14,16,17]$ and an increase in number, sensitivity and affinity for glutamate of NMDA receptors (up-regulation) $[10,14,18]$. More recently, an upregulation of glutamate receptors a-amino-3-hydroxy-5-methylisoxazole-4-propionic acid (AMPA) and kainate has been described during AWS [19, 20].

The abrupt reduction or cessation of alcohol intake produces an acute unbalance due both to the acute reduction of GABA activity and the increase of glutamatergic action, with consequent hyper excitability and development of AWS symptoms which may start as early as a few hours after the last alcohol intake [13]. The up-regulation of dopaminergic and noradrenergic pathways could be responsible for the development, respectively, of hallucinations and of autonomic hyperactivity during AWS [6].

"Kindling" is represented by an increased neuronal excitability and sensitivity after repeated episodes of AWS [21, 22]. "Kindling" has been proposed to explain the risk of progression of some patients from milder to more severe forms of AWS.

\section{AWS: identification of symptoms}

AWS should be considered among the possible differential diagnoses of patients with symptoms like those outlined in the Table 1 . Health care providers should ask patients about their drinking habits (duration, amount and frequency of alcohol consumption), the typical onset of symptoms after a few hours of alcohol abstinence (typically in the morning, at awakening), and past history of AWS. The Cut down-Annoyed-Guilty-Eye opener (CAGE) and Alcohol Use Disorders Identification Test (AUDIT) questionnaires [23] may help identifying AUD patients.

Furthermore, patients with reduced level of consciousness (i.e. trauma and general surgery patients) at risk for AWS have to be monitored for the appearance of AWS symptoms, and safely and effectively managed [24, 25].

AWS represents a continuous spectrum of symptoms ranging from mild withdrawal symptoms to delirium tremens (DT). AWS can start with mild symptoms and then evolve to more severe forms, or can start with DT, in particular in those patients with previous history of DT or with history of repeated AWS (kindling phenomenon). Usually, $1^{\text {st }}$ degree AWS symptoms (tremors, diaphoresis, nausea/vomiting, hypertension, tachycardia, hyperthermia, tachypnea) begin 6-12 hours after the last alcohol consumption, lasting until the next drink [26]. In co-morbid patients taking other medications such as $\beta$-blockers, significant changes in vital signs (blood pressure and heart rate) can be masked and appear normal. The $2^{\text {nd }}$ degree AWS symptoms are characterized by visual and tactile disturbances and generally start $24 \mathrm{~h}$ after the last drink. Almost $25 \%$ of AWS patients show transient alterations of perception $[27,28]$ such as auditory (voices), or, less frequently, visual (zooscopies) or tactile disturbances [26]. They may be persecutory and cause paranoia, leading to increased patient agitation [27]. When these symptoms become persistent, the patient has progressed to alcoholic hallucinosis. However, the patient recognizes the hallucinations as unreal, as dysperceptions, and maintains a clear sensorium [26]. 
Almost $10 \%$ of patients showing withdrawal symptoms develops alcohol withdrawal seizures $\left(3^{\text {rd }}\right.$ degree AWS) $[14,29]$, generally starting after $24-48 \mathrm{~h}$ from the last drink and characterized by diffuse, tonic-clonic seizures usually with little or no postictal period [29]. Even if self-limiting in the majority of cases, seizures can be difficult to treat and almost in one-third of patients, DT may represent a clinical worsening of alcohol withdrawal seizures [14].

Delirium tremens represents the most severe manifestation ( $4^{\text {th }}$ degree) of AWS, as the result of no treatment or undertreatment of AWS [6], and occurrs approximately in 5\% of patients with AWS [6]. Usually it appears 48-72h after the last drink, although it could begin up to 10 days later. Symptoms last normally $5-7$ days $[26,29,30]$. DT is characterised by a rapid fluctuation of consciousness and change in cognition occurring over a short period of time, accompanied by severe autonomic symptoms (sweating, nausea, palpitations and tremor) and psychological symptoms (i.e. anxiety) [6]. The typical DT patient shows agitation, hallucinations and disorientation. The presence of disorientation differentiates delirium from alcoholic hallucinosis. Delirium, psychosis, hallucinations, hyperthermia, malignant hypertension, seizures and coma are common manifestations of DT [26, 29, 31]. DT could be responsible of injury to patient or to staff, or of medical complications (aspiration pneumonia, arrhythmia or myocardial infarction), which may lead to death in $1-5 \%$ of patients [32, 33].

After the treatment of acute AWS, some symptoms can persist from weeks to months following the 5-7 days of acute detoxification period, representing the "protracted AWS" [6].

\section{AWS: diagnosis}

According to Diagnostic and Statistical Manual of mental disorders (DSM-5) criteria, the diagnosis of AWS is based on the observation of signs and symptoms of withdrawal in those patients who experienced an abrupt reduction or cessation of alcohol consumption [31]. DSM-5 requires the observation of at least two of the following symptoms: autonomic hyperactivity (sweating or tachycardia); increased hand tremor; insomnia; nausea or vomiting; transient visual, tactile or auditory hallucinations or illusions; psychomotor agitation; anxiety; and tonic-clonic seizures [31].

Moreover it is important to differentiate symptoms related to the acute or chronic alcohol abuse or withdrawal, from those related to other psychiatric disorders [34]. However, from a practical point of view, the use of a structured interview could be difficult, and it is conceptually unnecessary, because patients suffering from AWS usually show agitation and confusion. The Clinical Institute Withdrawal Assessment for Alcohol (CIWA-A) scale has emerged as a useful tool to assess AWS severity [35], particularly in the 10-item revised form (CIWA-Ar) [6, 36, 37]. The CIWA-Ar scale requires limited patient cooperation to evaluate its ten symptoms (table 2). Scores of less than 8 indicate mild withdrawal, 8-15 indicate moderate withdrawal (marked autonomic arousal) and $>15$ indicate severe withdrawal and are also predictive of the development of seizures and delirium [38, 39]. If CIWA-Ar score is $<8-10$ pharmacological treatment is not necessary, while it may be 
appropriate in those patients scoring between 8 and 15, to prevent the progression to more severe forms of AWS (see table 3). Pharmacological treatment is strongly indicated in patients with CIWA-Ar score $>15$. The evaluation of CIWA-Ar score should be repeated at least every 8 hours. In patients with scores $>8-10$ or requiring treatment, CIWA should be repeated every hour to evaluate the response to treatments.

The Alcohol Withdrawal Scale was developed in order to provide an assessment of AWS, even in those patients presenting with severe withdrawal and delirium, without requiring the patient's participation [40]. In this connection, "hallucinations" and "contact" items were included for a better identification of DT [40]. This scale consists of 2 subscales (S subscale: pulse rate, diastolic blood pressure, temperature, breathing rate, sweating, tremor; $\mathrm{M}$ subscale: agitation, contact, orientation, hallucination, anxiety) allowing a separate assessment of somatic and mental withdrawal symptoms. Mild AWS is identified by a total score 5; moderate AWS scores 6-9; severe AWS results in a score $\geq 10$ (table 4).

In clinical practice, physicians have the need to predict the probability of a patient to develop severe AWS. In particular, in those patients in whom a complete medical history is not available (i.e. emergency department, trauma unit, ICU), a high risk of complicated AWS could orientate the medical decision toward a more aggressive treatment, despite presenting symptoms.

The risk for severe AWS can be assessed by using the LARS (Luebeck Alcohol withdrawal Risk Scale) [41], or the recently proposed PAWSS (Prediction of Alcohol Withdrawal Severity Scale) [42].

A variety of clinical conditions could be associated with AWS both as complication of the disease or of the treatment [6]. In particular, infectious (i.e. pneumonia and sepsis) and neurological (Wernicke's encephalopathy) complications could be associated with immune and nutritional deficits related to AUD, or can be the direct consequence of the mechanical ventilation and/or ICU stay due to respiratory depression [4]. On this connection physicians should be aware of these risks in order to start an adequate treatment.

Moreover, it should be underlined that severe medical illnesses (i.e. pneumonia, coronary heart disease, alcohol liver disease and anaemia) have been reported to precipitate AWS and to increase the risk of severe AWS [33, 43]. In these patients a prophylactic treatment could be useful, regardless of CIWA score.

\section{AWS: treatment}

\subsection{Goals of the treatment}

AWS is a cause of severe discomfort to patients, symptoms are disabling and patients who experienced withdrawal, often are afraid to stop drinking for fear of developing withdrawal symptoms again. The main goal of the treatment is to minimize the severity of symptoms in order to prevent the more severe manifestations such as seizure, delirium and death and to improve the patient's quality of life $[6,44]$. Moreover an effective treatment of AWS should 
be followed by efforts in increasing patient motivation to maintain long-term alcohol abstinence and facilitate the entry into a relapse prevention program [6, 44].

Patients suffering from mild to moderate AWS can be managed as outpatients while more severe forms should be monitored and treated in an inpatient setting. The availability of an Alcohol Addiction Unit is of help in the clinical evaluation, management, and treatment of AWS patients, with a reduction in hospitalization costs. Patients can be managed principally as outpatients and transferred to the inpatient unit only when the clinical situation requires [45].

\subsection{General treatment and supportive care}

Non-pharmacologic interventions are the first-line approach and, sometimes, the only approach required. They include frequent reassurance, reality orientation, and nursing care [38]. A quiet room without dark shadows, noises, and other excessive stimuli (i.e. bright lights) is recommended [46].

Routine examination should include blood (or breath) alcohol concentration, complete blood count, renal function tests, electrolytes, glucose, liver enzymes, urinalysis and urine toxicology screening. General supportive care should correct fluid depletion, hypoglycemia and electrolytes disturbances, and should include hydration and vitamin supplementation. In particular, thiamine supplementation and B-complex vitamins (including folates) are essential for the prevention of Wernicke's encephalopathy (WE) [47]. Thiamine can be given routinely in these patients given the absence of significant adverse effects or contraindications [46]. Moreover, since the administration of glucose can precipitate or worsen WE, thiamine should be administered before any glucose infusion [48]. Finally, with the exception of patients with cardiac arrhythmias, electrolytes disturbances or previous history of AWS-related seizures, there is no evidence to support the routine administration of magnesium during AWS [49].

\subsection{Drugs for the treatment of AWS}

The treatment of AWS requires the use of a long-acting drug as a substitutive agent to be gradually tapered off [50] (figure 1).

The ideal drug for AWS should have a rapid onset and a long duration of action in reducing withdrawal symptoms and a relatively simple metabolism, not depending on liver function. It should not interact with alcohol, should suppress the "drinking behavior" without producing cognitive and/or motor impairment and it should not have a potential for abuse $[21,51,52]$.

\subsection{Benzodiazepines}

At present benzodiazepines (BZDs) represent the "gold-standard" in the treatment of AWS $[53,54]$. Furthermore, BZDs represent the only class of medications with proven efficacy in preventing the development of complicated forms of AWS, with a reduction in the incidence of seizures (84\%), DT and the associated risk of mortality [53, 55-57]. In particular, in the United States, BZDs are the first choice treatment, while in Europe, clomethiazole is also 
widely used [54]. The efficacy of BZDs in the treatment of AWS seems to be mediated by their stimulation of $\mathrm{GABA}_{\mathrm{A}}$ receptors with alcohol mimicking effects [50].

No study has shown a clear superiority of any agent over the others. The greater evidence exists for the long-acting agents (chlordiazepoxide and diazepam) [58, 59], given their ability to produce a smoother withdrawal [60]. The clinical effect is mediated by the drug (BZD) per se, and by its active metabolites produced by phase I liver oxidation.

Subsequently all products of oxidative metabolism are inactivated by phase II liver glucuronidation and excreted [21, 61]. However, in patients with reduced liver metabolism, such as in the elderly or in those with advanced liver disease, the use of short-acting agents may be preferred in order to prevent excessive sedation and respiratory depression [55]. In these cases, oxazepam and lorazepam represent the drugs of choice due to the absence of oxidative metabolism and active metabolites $[21,54,61]$ (table 5).

The possibility of multiple administration routes (oral, intramuscular [I.M.], or intravenous [I.V.]) represents an advantage of BZDs. The I.V. route should be preferred for moderate to severe AWS because of the rapid onset of action, while the oral route can be used in the milder forms. Chlorodiazepoxide and diazepam should not be administered I.M. due to their erratic absorption; lorazepam can be administered by all three routes; oxazepam can be administered only orally, while midazolam can be given intravenously as continuous infusion [60].

A "fixed-dose", rather than a "loading dose" or a "symptoms-triggered" regimen can be adopted for the management of AWS.

With the fixed-dose approach, the chosen drug (i.e. diazepam $10 \mathrm{mg}$ QID for 1 day, then 5 $\mathrm{mg}$ QID for 2 days, then tapering off; alternatively chlordiazepoxide 50-100 mg QID for 1 day, then 25-50 mg QID for 2 days, with subsequent tapering off) is given at regular intervals (independently from patient's symptoms), tapering off the dose by $25 \%$ per day from day 4 to day 7 . Additional doses can be administered if symptoms are not adequately controlled. This approach is highly effective and could be preferred in those patients at risk for severe AWS, or in those patients with history of seizures or DT (table 3). However patients should be monitored for the risk of excessive sedation and respiratory depression $[59,62]$.

The loading-dose strategy requires the administration of a moderate-to-high dose of a longacting benzodiazepine (i.e. diazepam 10-20 mg or chlordiazepoxide $100 \mathrm{mg}$, every 1-2 hours) in order to produce sedation; successively, drug levels will decrease (auto-taper) through metabolism. The risk of BZD toxicity is high during the early phase of the treatment and the patient requires a strict clinical monitoring to prevent BZD toxicity. However, this approach seems to produce the shorter treatment course secondary to the progressive autotapering of drug levels and to reduce the incidence of severe AWS promoting recovery from AWS [59].

The last scheme, symptom-triggered, is based on the administration of the chosen drug (diazepam 5-20 mg, chlordiazepoxide 50-100 mg or lorazepam 2-4 mg) if CIWA-Ar score is $>8-10$. Symptom severity is measured hourly. The dose is adjusted (i.e. from 5 to $10 \mathrm{mg}$ 
of diazepam) according to the severity of the symptoms [50], and can be repeated every hour until the CIWA-Ar score decreases to $<8$. The use of CIWA-Ar score seems to be useful and effective in the dose-adjustment of the drug.

Trials comparing different AWS treatment strategies did not find clear evidence of the superiority for one of these regimens [62-64]. However, the symptom-triggered regimen has been shown to reduce total BZD consumption and treatment duration with respect to fixeddose in patients at low risk for complicated AWS [53].

From a practical point of view, in an inpatients setting in which an intensive care unit (ICU) is rapidly available the front-loading scheme could be safely chosen. On the contrary, if ICU is not available but a strict clinical observation is possible, symptom-triggered regimen could be preferred in order to reach the clinical effect with the minimum BZD administration. The fixed-dose treatment represents the recommended regimen in those patients at risk for complicated AWS, with history of seizures or DT (in whom drugs should be administered regardless of the symptoms) [60].

BZDs administration represents the cornerstone for the management of any grade of AWS, including seizures and DT. In particular, the European Federation of Neurological Societies recommends the use of benzodiazepines for the primary prevention and for the treatment of AWS-related seizures. The drugs of choice are lorazepam and diazepam. Although lorazepam has some pharmacological advantages to diazepam, the differences are minor and, because i.v. lorazepam is largely unavailable in Europe, diazepam is recommended. Other drugs for detoxification should only be considered as add-on treatments (Level A recommendation) [65]. Despite its primary indication as anticonvulsivant drug, phenytoin has been shown to be ineffective in the secondary prevention of alcohol withdrawal seizures in placebo-controlled trials [66]. Thus its use should be avoided.

Treatment of DT requires the use of BZDs as primary drugs, with the possible use of neuroleptics to control psychosis and dysperceptions (see further).

The use of BZDs is, however, associated with increased risk of excessive sedation, motor and memory deficits and respiratory depression, and these effects are more pronounced in patients with liver impairment [54]. Moreover the risk of abuse and dependence [51, 67] limits BZD use in AD patients [54].

\subsection{Barbiturates and propofol}

The use of barbiturates in the treatment of AWS has been limited given their narrow therapeutic window, the risk of excessive sedation and the interference with the clearance of many drugs $[46,68]$. However, in the setting of ICU, in those patients requiring high doses of BZDs to control AWS symptoms or developing DT, barbiturates maintain a specific indication. The combination of phenobarbital with benzodiazepines promotes BZD binding to the $\mathrm{GABA}_{\mathrm{A}}$ receptor, possibly increasing the efficacy of the benzodiazepine action [69]. In patients affected by severe DT requiring mechanical ventilation, the combination of benzodiazepines and barbiturates produces both a decrease in the need of mechanical ventilation and a trend towards a decrease in ICU length of stay [70]. 
In the ICU setting, propofol is a promising drug. The main advantages are represented by its antagonist effect on the NMDA receptor, by $\mathrm{GABA}_{\mathrm{A}}$ stimulation, and by its short duration of effect, that allows a rapid evaluation of patient's mental status after discontinuation [71, 72]. These characteristics make propofol a useful therapeutic option in patients with severe delirium tremens, who are poorly controlled with high doses of benzodiazepines [73]. However, the use of this drug requires clinical monitoring, endotracheal intubation and mechanical ventilation. In the setting of ICU, in those patients requiring sedation and mechanical ventilation, the Sedation-Agitation Scale (SAS) or the Richmond AgitationSedation Scale (RASS) can be used to titrate sedation [2-70].

\subsection{Other Drugs}

More recently, other drugs have been investigated as treatments for AWS (figure 1).

5.6.1 Alpha 2 -agonists, beta-blockers and neuroleptics-These classes of medications have been tested and are currently used as adjunctive treatment for AWS. However, the lack of efficacy in preventing severe AWS and the risk of masking AWS symptoms make these drugs not recommended as monotherapy. They should be used only as adjunctive treatment, in patients with co-existing comorbidities, and to control neuroautonomic manifestations of AWS when not adequately controlled by BZDs administration.

The administration of these drugs as monotherapy could mask AWS symptoms and reduce CIWA-Ar scores with a consequent reduction of the prescription of BZDs and possible risk to develop complicated AWS.

Beta-blockers (e.g. atenolol) could be used to treat hyperarousal symptoms in patients with coronary artery disease [74]. However, given their effect on tremors, tachycardia and hypertension, these drugs could mask AWS symptoms and should be considered only in conjunction with BZDs in patients with persistent hypertension or tachycardia [54].

The use of alpha ${ }_{2}$-agonists could have a role in the management of AWS. Parenteral administration of clonidine may be associated with sedation and other side effects, while low doses of clonidine (oral, transdermal) may have a role in the control of AWS symptoms via a reduction of autonomic hyperactivity (hypertension and tachycardia) [75]. The use of dexmedetomidine, a more selective alfa2-receptor agonist, showed interesting results in controlling sympathetic symptoms with less sedation than clonidine as adjunctive drug to lorazepam for severe AWS, and with a possible BZD-sparing effect. However, bradycardia was a commonly observed side-effect. Moreover, these results require further investigations and validation [76].

Neuroleptics (i.e., haloperidol) are generally used for the management of hallucinosis and delirium. However, given their lack of effect in preventing the worsening of AWS, their facilitating effect on the development of seizures and the risk of QT prolongation, the use of neuroleptic agents as monotherapy is contraindicated. Moreover they are associated with a longer duration of delirium, higher complication rate and higher mortality [77]. The use of neuroleptics should be reserved as adjunctive treatment in the case of agitation, perceptual disturbances, or disturbed thinking not adequately controlled by BZDs [54]. 
5.6.2 Carbamazepine-Carbamazepine is a tricyclic anticonvulsant able to produce a GABAergic effect and to block NMDA receptors [78]. It has been shown to be an effective drug in the treatment of AWS, at least in mild to moderate forms, producing an effect superior to placebo and non-inferior to BZDs [60,78]. The proposed treatment scheme is $600-800 \mathrm{mg} /$ day on day 1 , tapered down to $200 \mathrm{mg}$ over 5 days [7]. A reduction of alcohol relapse has also been showed in the post-AWS phase [7, 79]. However, side effects associated with long-term administration (i.e. nausea, vomiting, dermatitis, Steven-Johnson syndrome, agranulocitosis) could limit its extensive use. Moreover, given its drug-drug interaction potential, this drug may be difficult to manage in patients with in patients with multiple comorbidities and treated with other medications [80]. Oxcarbazepine (900 $\mathrm{mg}$ for 3 days, $450 \mathrm{mg}$ for 4 th day, $150 \mathrm{mg}$ for 5 th day), a metabolite of carbamazepine, due to the only weak induction of Cytochrome P450 and the kidney excretion, could represent a valid alternative to carbamazepine [6]. However its role in AWS remains to be completely demonstrated.

5.6.3 Valproate-Valproic acid (400-500 $\mathrm{mg}$ tid) is able to produce a dose-dependent improvement of AWS symptoms [6,81], with a reduced incidence of seizures and a protection toward the worsening of AWS severity (anti-kindling effect). These characteristics make valproic acid an interesting and promising drug in the outpatient management of mild-to-moderate forms of AWS [82]. The most commonly observed sideeffects were gastrointestinal distress, tremor and sedation [22]. The possible increase of liver enzymes (transaminases) could limit its use in AD patients with liver impairment.

5.6.4 Sodium Oxybate-Sodium Oxybate (SMO) also called gamma-hydroxybutyric acid is a short-chain fatty acid that occurs naturally in mammalian brain, in particular in the thalamus, hypothalamus and basal ganglia. SMO is structurally similar to the inhibitory neurotransmitter GABA, binding to $\mathrm{SMO}$ and $\mathrm{GABA}_{\mathrm{B}}$ receptors with high and low affinity, respectively [83]. Given SMO's alcohol-mimicking effects on CNS [84], this drug was tested in preclinical and clinical setting for the treatment of AWS [85]. The efficacy of repeated doses of SMO $(50 \mathrm{mg} / \mathrm{kg} /$ day in three divided doses $)$ has been shown in comparative studies versus benzodiazepines [86, 87] and versus clomethiazole [88]. In almost all studies of SMO in patients with AWS in different clinical setting, the primary efficacy endpoint was the decrease of the CIWA-Ar score and/or CIWA-Ar subscores [36]. A meta-analysis performed in 2010 by The Cochrane Collaboration showed that SMO (50 $\mathrm{mg} / \mathrm{kg} /$ day) is more effective than placebo in reducing AWS symptoms score, with an efficacy equivalent to benzodiazepines and clomethiazole. No differences between the groups were observed for side effects and numbers of drop-outs between treatments [89]. Recently the GATE 1 study, a phase IV, multicenter, multinational, randomized, active drugcontrolled study (double-blind, double dummy), with parallel groups evidenced the efficacy of SMO and non-inferiority of SMO vs oxazepam in the treatment AWS [90]. The efficacy and the safety of oral SMO in the long-term treatment of alcohol dependence, [85, 89], makes this drug useful in the treatment of both AWS and long-term treatment for alcohol relapse prevention. 
SMO has been approved in some European countries for the treatment of alcohol withdrawal syndrome (AWS) and for relapse prevention and maintenance of abstinence. It is not approved for this indication in other countries, as its addictive properties limit its use [91]. However, at therapeutic doses for the treatment of alcohol-dependent patients SMO abuse seems to be a relatively limited phenomenon [92]. Future studies are needed to clarify these aspects.

5.6.5 Baclofen-Baclofen is a $\mathrm{GABA}_{\mathrm{B}}$ receptor agonist, currently used to control spasticity [93]. Baclofen is able to reduce AWS by activating $\mathrm{GABA}_{B}$ receptors that might offset AWS-associated enhanced function of NMDA receptors [94]. Moreover baclofen is able to prevent the sensitization of withdrawal anxiety caused by repeated withdrawals [95].

A randomized single-blind study comparing baclofen (10 $\mathrm{mg}$ tid for 10 days) vs. diazepam $(0.5-0.75 \mathrm{mg} / \mathrm{kg} / \mathrm{day}$ for 6 consecutive days, tapering the dose by $25 \%$ daily from day 7 to day 10) in the treatment AWS did not find any significant differences between the two drugs in CIWA-Ar score reductions [96]. Moreover, the oral route administration [96, 97] gave the possibility of an outpatient treatment regimen, resulting in a significant reduction in the cost of treatment compared to inpatient AWS treatment.

A more recent double-blind placebo-controlled trial found that the use of baclofen was associated with a significant reduction in the use of 'as-needed' lorazepam in the management of AWS [98]. Furthermore some clinical evidence suggests that the use baclofen could have a potential role in the prophylaxis of AWS in hospitalized patients at risk for AWS [99].

Baclofen seems to be an easily manageable drug, without significant side effects. At the prescribed doses, there have not been any reports of euphoria or other pleasant effects caused by the drug. Although these data are encouraging, further confirmatory studies are needed to establish the role of baclofen in AWS. Baclofen showed its efficacy in alcohol relapse prevention $[100,101]$ suggesting that it could represent a promising drug in the treatment of both AWS and post-withdrawal [102]. The lack of any significant side effect and of liver toxicity [103] makes it possible to use this drug for the treatment of AUD patients affected by liver disease [104].

5.6.6 Gabapentin-Gabapentin is a medication structurally similar to GABA, approved for the adjunctive treatment of partial seizures. Its final effect seems to be an amplification of brain GABA synthesis [105]. At present, data on the efficacy of gabapentin in the treatment of AWS are controversial. Preliminary clinical studies suggest the possible efficacy of gabapentin in the treatment of AD patients affected by AWS ( $400 \mathrm{mg}$ tid for 3 days, $400 \mathrm{mg}$ bid for 1 day, then $400 \mathrm{mg}$ for 1 day) [106, 107]. In a retrospective study analyzing both out- and inpatients treated with gabapentin, the drug seemed to be effective in the treatment of mild-to-moderate AWS, while it was less effective in severe AWS [108]. More recently the safety and effectiveness of gabapentin in the treatment of tonic-clonic seizures associated with AWS have been demonstrated [109]. An open-label study conducted with 27 inpatients compared gabapentin to phenobarbital and demonstrated no difference between the two drugs [110]. However, in a double-blind placebo-controlled trial, 
gabapentin was not more effective than placebo in the management of AWS [111]. A possible explanation of this lack of effect could be the too low entry dose. Moreover, it has been speculated that gabapentin's effects are at least partially related to its sedative effects, that could be useful in the treatment of the sleep disturbances typically present during AWS [112]. In summary, further confirming data are required on the possible utility of gabapentin in AWS [113]. If confirmed, also gabapentin would be an interesting option in the treatment of AD patients, from AWS to alcohol relapse prevention [114, 115].

5.6.7 Topiramate-Topiramate is an anticonvulsant with several mechanisms of action. In particular, topiramate produces an increase in $\mathrm{GABA}_{\mathrm{A}}$ receptor-mediated inhibitory activity and antagonizes AMPA and kainate glutamate receptors with a consequent reduction in DA release in the nucleus accumbens. It is able to modulate ionotropic channels, inhibiting Ltype calcium channels, limiting the activity of voltage-dependent sodium channels and facilitating potassium conductance. All these effects are at the basis of topiramate's ability to reduce the hyperactivity and resulting anxiety of AWS [116].

Open-label studies showed the efficacy of topiramate (50 $\mathrm{mg}$ bid or once a day) in reducing the incidence of AWS seizures [117] and symptoms [118]. The ability of topiramate to produce an effect on multiple neurotransmitter systems represents the rationale for the use of topiramate in the treatment of AWS [119]. Considering these preliminary data of topiramate in AWS, and its efficacy in promoting alcohol abstinence [116, 120, 121], topiramate too could represent an interesting pharmacological option for the treatment of AUD from AWS to long-term detoxification [105].

\section{Conclusions}

AWS represents a potentially life-threatening medical condition typically affecting AUD patients abruptly decreasing or stopping alcohol consumption. AWS should be considered in the differential diagnosis of any patients showing symptoms of autonomic hyperactivity. The use of a clinician-administered scale (CIWA-Ar or Alcohol Withdrawal Scale) is important to diagnose AWS and start adequate treatment. BZDs represent the gold standard treatment as a result both for their high rate of efficacy and being the only medications with proven ability to prevent the complicated forms of AWS (seizures, DTs).

The treatment of AWS may be challenging. The initial phase is characterized by patient agitation and non-collaboration. This phase should be aggressively treated, in order to reduce the risk of medical complications (seizures, DTs, death), reduce patient suffering and improve quality of life. The direct effect of these measures will be, in most of cases, a strong physician-patient relationship. The latter is necessary to improve patient's disposition toward medical management and to start a long-term, multidisciplinary treatment of alcohol dependence.

While BZD's addictive properties limit their long-term use [67], the possibility of using other pharmacological agents able to be effective both for the treatment of AWS and the subsequent long-term program for alcohol relapse prevention represents an advantage, i.e. carbamazepine, SMO, baclofen, gabapentin and topiramate. 
The early administration of a non-BZD agent together with gold-standard treatments represents a useful option to reduce the need for extra-dose BZD prescription (BZD-sparing drugs) [98] and to start a medication with anti-craving properties (figure 1).

However, it is important to keep in mind that at present, BZDs are the most effective and manageable drugs for the treatment of AWS.

\section{Acknowledgments}

This study was supported by the Italian Ministry for University, Scientific and Technological Research (MURST); AM, CDA, AF, GV, MA, FC, AG, GA. LL is a federal employee in the Section on Clinical Psychoneuroendocrinology and Neuropsychopharmacology, which is supported by the Division of Intramural Clinical and Biological Research of the National Institute on Alcohol Abuse and Alcoholism (NIAAA) and the Intramural Research Program of the National Institute on Drug Abuse (NIDA) (the content of this review is solely the responsibility of the authors and does not necessarily represent the official views of the National Institutes of Health).

\section{References}

1. Hasin DS, Stinson FS, Ogburn E, et al. Prevalence, correlates, disability, and comorbidity of DSMIV alcohol abuse and dependence in the United States: results from the National Epidemiologic Survey on Alcohol and Related Conditions. Arch Gen Psychiatry. 2007; 64:830-842. [PubMed: 17606817]

2. Whiteman PJ, Hoffman RS, Goldfrank LR. Alcoholism in the emergency department: an epidemiologic study. Acad Emerg Med. 2000; 7:14-20. [PubMed: 10894237]

3. Awissi DK, Lebrun G, Fagnan M, et al. Alcohol, nicotine, and iatrogenic withdrawals in the ICU. Crit Care Med. 2013; 41(9 Suppl 1):S57-S68. [PubMed: 23989096]

4. Saitz R. Clinical practice. Unhealthy alcohol use. N Engl J Med. 2005; 352:596-607. [PubMed: 15703424]

5. Hall W, Zador D. The alcohol withdrawal syndrome. Lancet. 1997; 349:1897-1900. [PubMed: 9217770]

6. McKeon A, Frye MA, Delanty N. The alcohol withdrawal syndrome. J Neurol Neurosurg Psychiatry. 2008; 79:854-862. [PubMed: 17986499]

7. Leggio L, Kenna GA, Swift RM. New developments for the pharmacological treatment of alcohol withdrawal syndrome. A focus on non-benzodiazepine GABAergic medications. Prog Neuropsychopharmacol Biol Psychiatry. 2008; 32:1106-1117. [PubMed: 18029075]

8. Mokdad AH, Marks JS, Stroup DF, et al. Actual causes of death in the United States, 2000. JAMA. 2004; 291:1238-1245. [PubMed: 15010446] Erratum. JAMA. 2005; 293:293-294. [PubMed: 15657315]

9. Malcolm RJ. GABA systems, benzodiazepines, and substance dependence. J Clin Psychiatry. 2003; (64 Suppl 3):36-40. [PubMed: 12662132]

10. Davis KM, Wu J-Y. Role of glutamatergic and GABAergic systems in alcoholism. J Biomed Sci. 2001; 8:7-19. [PubMed: 11173971]

11. Chastain G. Alcohol, neurotransmitter systems, and behavior. J Gen Psychol. 2006; 133:329-335. [PubMed: 17128954]

12. Addolorato G, Abenavoli L, Leggio L, et al. How many cravings? Pharmacological aspects of craving treatment in alcohol addiction: a review. Neuropsychobiology. 2005; 51:59-66. [PubMed: 15741745]

13. Littleton J. Neurochemical mechanisms underlying alcohol withdrawal. Alcohol Health Res World. 1998; 22:13-24. [PubMed: 15706728]

14. Gold, J.; Nelson, LS. Ethanol withdrawal. In: Nelson, LS.; Lewin, NA.; Howland, MA.; Hoffman, RS.; Goldfrank, LR.; Flomenbaum, NE., editors. Goldfrank's toxicologic emergencies. 9th. New York, NY: McGraw-Hill; 2011. p. 1134-1142. 
15. Fadda F, Rossetti ZL. Chronic ethanol consumption: from neuroadaptation to neurodegeneration (review). Progr Neurobiol. 1998; 56:385-431.

16. Allan AM, Harris RA. Acute and chronic ethanol treatments alter GABA receptoroperated chloride channels. Pharmacol Biochem Behav. 1987; 27:665-670. [PubMed: 2443933]

17. Cagetti E, Liang J, Spigelman I, et al. Withdrawal from chronic intermittent ethanol treatment changes subunit composition, reduces synaptic function, and decreases behavioral responses to positive allosteric modulators of GABAA receptors. Mol Pharmacol. 2003; 63:53-64. [PubMed: 12488536]

18. Engberg G, Hajos M. Alcohol withdrawal reaction as a result of adaptive changes of excitatory amino acid receptors. Naunyn Schmiedebergs Arch Pharmacol. 1992; 346:437-441. [PubMed: 1436128]

19. Carta M, Olivera DS, Dettmer TS, et al. Ethanol withdrawal upregulates kainate receptors in cultured rat hippocampal neurons. Neurosci Lett. 2002; 327:128-132. [PubMed: 12098652]

20. Haugbøl SR, Ebert B, Ulrichsen J. Upregulation of glutamate receptor subtypes during alcohol withdrawal in rats. Alcohol Alcohol. 2005; 40:89-95. [PubMed: 15569719]

21. Lejoyeux M, Solomon J, Adès J. Benzodiazepine treatment for alcohol-dependent patients. Alcohol Alcohol. 1998; 33:563-575. [PubMed: 9872344]

22. Reoux JP, Saxon AJ, Malte CA, et al. Divalproex sodium in alcohol withdrawal: a randomized double-blind placebo-controlled clinical trial. Alcohol Clin Exp Res. 2001; 25:1324-1329. [PubMed: 11584152]

23. National Institute on Alcohol Abuse and Alcoholism. Helping patients with alcohol problems: a health practitioner's guide. Bethesda, Md: U.S. Dept. of Health and Human Services, National Institutes of Health, National Institute on Alcohol Abuse and Alcoholism; 2003. NIH publication no. 03-3769

24. Eggers V, Tio J, Neumann T, et al. Blood alcohol concentration for monitoring ethanol treatment to prevent alcohol withdrawal in the intensive care unit. Intensive Care Med. 2002; 28:1475-1482. [PubMed: 12373474]

25. Stanley KM, Amabile CM, Simpson KN, et al. Impact of an alcohol withdrawal syndrome practice guideline on surgical patient outcomes. Pharmacotherapy. 2003; 23:843-854. [PubMed: 12885097]

26. Victor M, Adams RD. The effect of alcohol on the nervous system. Res Publ Assoc Res NervMent Dis. 1953; 32:526-573.

27. Victor M, Hope JM, Adams RD. Auditory hallucinations in the alcoholic patient. Trans Am Neurol Assoc. 1953; 3:273-275. [PubMed: 13179238]

28. Victor M. Treatment of the neurologic complications of alcoholism. Mod Treat. 1966; 3:491-501. [PubMed: 5326563]

29. Victor M, Brausch C. The role of abstinence in the genesis of alcoholic epilepsy. Eplilepsia. 1967; $8: 1-20$.

30. Wolf KM, Shaughnessy AF, Middleton DB. Prolonged delirium tremens requiring massive dosages of medication. J Am Board Fam Pract. 1993; 6:502-504. [PubMed: 8213241]

31. American Psychiatric Association. Diagnostic and statistical manual of mental disorders. 5th. Arlington: American Psychiatric Association; 2013.

32. Kasser, C.; Geller, A.; Howell, E., et al. Detoxification: principles and protocols. American Society of Addiction Medicine. http://www.asam.org/publ/detoxification.htm

33. Schuckit MA, Tipp JE, Reich T, et al. The histories of withdrawal convulsions and delirium tremens in 1648 alcohol dependent subjects. Addiction. 1995; 90:1335-1347. [PubMed: 8616462]

34. Torrens M, Martin-Santos R, Samet S. Importance of clinical diagnoses for comorbidity studies in substance use disorders. Neurotox Res. 2006; 10:253-261. [PubMed: 17197374]

35. Shaw JM, Kolesar GS, Sellers EM, et al. Development of optimal treatment tactics for alcohol withdrawal. I. Assessment and effectiveness of supportive care. J Clin Psychopharmacol. 1981; 1:382-389. [PubMed: 7334148]

36. Sullivan JT, Sykora K, Schneiderman J, et al. Assessment of alcohol withdrawal: the revised clinical institute withdrawal assessment for alcohol scale (CIWA-Ar). Br J Addict. 1989; 84:13531357. [PubMed: 2597811] 
37. Sullivan JT, Swift RM, Lewis DC. Benzodiazepine requirements during alcohol withdrawal syndrome: clinical implications of using a standardized withdrawal scale. J Clin Psychopharmacol. 1991; 11:291-295. [PubMed: 1684974]

38. Naranjo CA, Sellers EM, Chater K, et al. Nonpharmacologic intervention in acute alcohol withdrawal. Clin Pharmacol Ther. 1983; 34:214-219. [PubMed: 6872416]

39. Young GP, Rores C, Murphy C, et al. Intravenous phenobarbital for alcohol withdrawal and convulsions. Ann Emerg Med. 1987; 16:847-850. [PubMed: 3619162]

40. Wetterling T, Kanitz RD, Besters B, et al. A new rating scale for the assessment of the alcoholwithdrawal syndrome (AWS scale). Alcohol Alcohol. 1997; 32:753-760. [PubMed: 9463730]

41. Wetterling T, Weber B, Depfenhart M, et al. Development of a rating scale to predict the severity of alcohol withdrawal syndrome. Alcohol Alcohol. 2006; 41:611-615. [PubMed: 16980710]

42. Maldonado JR, Sher Y, Ashouri JF, et al. The "Prediction of Alcohol Withdrawal Severity Scale" (PAWSS): systematic literature review and pilot study of a new scale for the prediction of complicated alcohol withdrawal syndrome. Alcohol. 2014; 48:375-390. [PubMed: 24657098]

43. Lee JH, Jang MK, Lee JY, et al. Clinical predictors for delirium tremens in alcohol dependence. J Gastroenterol Hepatol. 2005; 20:1833-1837. [PubMed: 16336440]

44. O'Connor PG, Schottenfeld RS. Patients with alcohol problems. N Engl J Med. 1998; 338:592602. [PubMed: 9475768]

45. Addolorato G, Mirijello A, Leggio L, et al. Liver transplantation in alcoholic patients: impact of an alcohol addiction unit within a liver transplant center. Alcohol Clin Exp Res. 2013; 37:1601-1608. [PubMed: 23578009]

46. Blondell RD. Ambulatory detoxification of patients with alcohol dependence. Am Fam Physician. 2005; 71:495-502. [PubMed: 15712624]

47. Cook CC, Thomson AD. B-complex vitamins in the prophylaxis and treatment of WernickeKorsakoff syndrome. Br J Hosp Med. 1997; 57:461-465. [PubMed: 9274684]

48. Hack JB, Hoffman RS. Thiamine before glucose to prevent Wernicke encephalopathy: examining the conventional wisdom. JAMA. 1998; 279:583. [PubMed: 9486750]

49. Sarai M, Tejani AM, Chan AH, et al. Magnesium for alcohol withdrawal. Cochrane Database Syst Rev. 2013; 6 CD008358.

50. Kosten TR, O'Connor PG. Management of drug and alcohol withdrawal. N Engl J Med. 2003; 348:1786-1795. [PubMed: 12724485]

51. Malcolm R, Myrick H, Brady KT, et al. Update on anticonvulsants for the treatment of alcohol withdrawal. Am J Addict. 2001; (10 Suppl):16-23. [PubMed: 11268817]

52. Malcolm RJ. GABA systems, benzodiazepines, and substance dependence. J Clin Psychiatry. 2003; (64 Suppl 3):36-40. [PubMed: 12662132]

53. Saitz R, Mayo-Smith MF, Roberts MS, et al. Individualized treatment for alcohol withdrawal. A randomized double-blind controlled trial. JAMA. 1994; 272:519-523. [PubMed: 8046805]

54. Mayo-Smith MF. Pharmacological management of alcohol withdrawal: a meta-analysis and evidence-based practice guideline. JAMA. 1997; 278:144-151. [PubMed: 9214531]

55. Amato L, Minozzi S, Davoli M. Efficacy and safety of pharmacological interventions for the treatment of the Alcohol Withdrawal Syndrome. Cochrane Database Syst Rev. 2011 Jun 15.(6) CD008537.

56. Holbrook AM, Crowther R, Lotter A, et al. Meta-analysis of benzodiazepine use in the treatment of acute alcohol withdrawal. CMAJ. 1999; 160:649-655. [PubMed: 10101999]

57. Adinoff B. Double-blind study of alprazolam, diazepam, clonidine, and the placebo in the alcohol withdrawal syndrome. Alcohol Clin Exp Res. 1994; 18:873-878. [PubMed: 7978098]

58. Ntais C, Pakos E, Kyzas P, et al. Benzodiazepines for alcohol withdrawal. Cochrane Database Syst Rev. 2005; (3) CD005063.

59. Muzyk AJ, Leung JG, Nelson S, et al. The role of diazepam loading for the treatment of alcohol withdrawal syndrome in hospitalized patients. Am J Addict. 2013; 22:113-118. [PubMed: 23414495]

60. Perry EC. Inpatient management of acute alcohol withdrawal syndrome. CNS Drugs. 2014; 28:401-410. [PubMed: 24781751] 
61. Peppers MP. Benzodiazepines for alcohol withdrawal in the elderly and in patients with liver disease. Pharmacotherapy. 1996; 16:49-57. [PubMed: 8700792]

62. Daeppen J-B, Gache P, Landry U, et al. Symptom-triggered vs fixed-schedule doses of benzodiazepine for alcohol withdrawal. Arch Intern Med. 2002; 162:1117-1121. [PubMed: 12020181]

63. Maldonado JR, Nguyen LH, Schader EM, et al. Benzodiazepine loading versus symptom-triggered treatment of alcohol withdrawal: a prospective, randomized clinical trial. Gen Hosp Psychiatry. 2012; 34:611-617. [PubMed: 22898443]

64. Spies CD, Otter HE, Huske B, et al. Alcohol withdrawal severity is decreased by symptomorientated adjusted bolus therapy in the ICU. Intensive Care Med. 2003; 29:2230-2238. [PubMed: 14557857]

65. Brathen, G.; Ben-Menachem, E.; Brodtkorb, E., et al. Alcohol-related seizures. In: Gilhus, NE.; Barnes, MP.; Brainin, M., editors. European Handbook of Neurological Management. 2nd. Vol. 1. 2011.

66. Hillbom M, Pieninkeroinen I, Leone M. Seizures in alcohol-dependent patients: epidemiology, pathophysiology and management. CNS Drugs. 2003; 17:1013-1030. [PubMed: 14594442]

67. Lugoboni F, Mirijello A, Faccini M, et al. Quality of life in a cohort of high-dose benzodiazepine dependent patients. Drug Alcohol Depend. 2014; 142C:105-109. [PubMed: 25001277]

68. Prater CD, Miller KE, Zylstra RG. Outpatient detoxification of the addicted or alcoholic patient. Am Fam Physician. 1999; 60:1175-1183. [PubMed: 10507746]

69. Mihic, SJ.; Harris, RA. Hypnotics and sedatives. In: Brunton, LL.; Chabner, BA.; Knollman, BC., editors. Goodman and Gilman's the pharmacological basis of therapeutics. 12th. New York: McGraw-Hill; 2011. p. 457-480.

70. Gold JA, Rimal B, Nolan A, et al. A strategy of escalating doses of benzodiazepines and phenobarbital administration reduces the need for mechanical ventilation in delirium tremens. Crit Care Med. 2007; 35:724-730. [PubMed: 17255852]

71. Hans P, Bonhomme V, Collette J, et al. Propofol protects cultured rat hippocampal neurons against N-methyl-D-aspartate receptor-mediated glutamate toxicity. J Neurosurg Anesthesiol. 1994; 6:249-253. [PubMed: 7528074]

72. Irifune M, Takarada T, Shimizu Y, et al. Propofol-induced anesthesia in mice is mediated by gamma-aminobutyric acid-A and excitatory amino acid recptors. Anesth Analg. 2003; 97:424429. [PubMed: 12873929]

73. McCowan C, Marik P. Refractory delirium tremens treated with propofol: a case series. Crit Care Med. 2000; 28:1781-1784. [PubMed: 10890619]

74. Bayard M, McIntyre J, Hill KR, et al. Alcohol withdrawal syndrome. Am Fam Physician. 2004; 69:1443-1450. [PubMed: 15053409]

75. Muzyk AJ, Fowler JA, Norwood DK, et al. Role of a2-agonists in the treatment of acute alcohol withdrawal. Ann Pharmacother. 2011; 45:649-657. [PubMed: 21521867]

76. Mueller SW, Preslaski CR, Kiser TH, et al. A randomized, double-blind, placebo-controlled dose range study of dexmedetomidine as adjunctive therapy for alcohol withdrawal. Crit Care Med. 2014; 42:1131-1139. [PubMed: 24351375]

77. Mayo-Smith MF, Beecher LH, Fischer TL, et al. Management of alcohol withdrawal delirium. An evidence-based practice guideline. Arch Intern Med. 2004; 164:1405-1412. [PubMed: 15249349]

78. Barrons R, Roberts N. The role of carbamazepine and oxcarbazepine in alcohol withdrawal syndrome. J Clin Pharm Ther. 2010; 35:153-167. [PubMed: 20456734]

79. Mueller TI, Stout RL, Rudden S, et al. A double-blind, placebo-controlled pilot study of carbamazepine for the treatment of alcohol dependence. Alcohol Clin Exp Res. 1997; 21:86-92. [PubMed: 9046378]

80. Pippenger CE. Clinically significant carbamazepine drug interactions: an overview. Epilepsia. 1987; (28 Suppl 3):S71-S76. [PubMed: 3319544]

81. Reoux JP, Saxon AJ, Shen D. Pharmacokinetic profile of an oral loading dose of divalproex sodium during acute alcohol withdrawal. J Clin Psychopharmacol. 2006; 26:105-107. [PubMed: 16415725] 
82. Muncie HL Jr, Yasinian Y, Oge' L. Outpatient management of alcohol withdrawal syndrome. Am Fam Physician. 2013; 88:589-595. [PubMed: 24364635]

83. Snead OC, Gibson KM. Gamma-hydroxybutyric acid. N Engl J Med. 2005; 352:2721-2732. [PubMed: 15987921]

84. Gessa GL, Agabio R, Carai M, et al. Mechanism of the anti-alcohol effect of gamma hydroxybutyric acid (GHB). Alcohol. 2000; 20:271-276. [PubMed: 10869869]

85. Skala K, Caputo F, Mirijello A, et al. Sodium oxybate in the treatment of alcohol dependence: from the alcohol withdrawal syndrome to the alcohol relapse prevention. Expert Opin Pharmacother. 2014; 15:245-257. [PubMed: 24283802]

86. Addolorato G, Balducci G, Capristo E, et al. Gamma-hydroxybutyric acid (GHB) in the treatment of alcohol withdrawal syndrome: a randomized comparative study versus benzodiazepine. Alcohol Clin Exp Res. 1999; 23:1596-1604. [PubMed: 10549990]

87. Nava F, Premi S, Manzato E, et al. Gamma-hydroxybutyrate reduces both withdrawal syndrome and hypercortisolism in severe abstinent alcoholics: an open study vs. diazepam. Am J Drug Alcohol Abuse. 2007; 33:379-392. [PubMed: 17613965]

88. Nimmerrichter AA, Walter H, Gutierrez-Lobos KE, et al. Double blind controlled trial ofgammahydroxybutyrate andclomethiazole in the treatment of alcohol withdrawal. Alcohol Alcohol. 2002; 37:67-73. [PubMed: 11825860]

89. Leone MA, Vigna-Taglianti F, Avanzi GC, et al. Gamma-hydroxybutyrate (GHB) fortreatment of alcohol withdrawal andprevention of relapses. Cochrane Database Syst Rev. 2010; (2) CD006266.

90. Caputo F, Skala K, Mirijello A, et al. Sodium Oxybate in the Treatment of Alcohol Withdrawal Syndrome: A Randomized Double-Blind Comparative Study versus Oxazepam. The GATE 1 Trial. CNS Drugs. 2014; 28:743-752. [PubMed: 24996524]

91. Tunnicliff G, Raess BU. Gamma-Hydroxybutyrate (orphan medical). Curr Opin Investig Drugs. 2002; 3:278-283.

92. Addolorato G, Leggio L, Ferrulli A, et al. The therapeutic potential of gamma-hydroxybutyric acid for alcohol dependence: balancing the risks and benefits. A focus on clinical data. Expert Opin Investig Drugs. 2009; 18:675-686.

93. Addolorato G, Leggio L. Safety and efficacy of baclofen in the treatment of alcohol-dependent patients. Curr Pharm Des. 2010; 16:2113-2117. [PubMed: 20482507]

94. Colombo G, Agabio R, Carai MA, et al. Ability of baclofen in reducing alcohol intake and withdrawal severity: I--Preclinical evidence. Alcohol Clin Exp Res. 2000; 24:58-66. [PubMed: 10656194]

95. Knapp DJ, Overstreet DH, Breese GR. Baclofen blocks expression and sensitization of anxiety-like behavior in an animal model of repeated stress and ethanol withdrawal. Alcohol Clin Exp Res. 2007; 31:582-595. [PubMed: 17374037]

96. Addolorato G, Leggio L, Abenavoli L, et al. Baclofen in the treatment of alcohol withdrawal syndrome: a comparative study vs diazepam. Am J Med. 2006; 119 276.e13-8.

97. Addolorato G, Caputo F, Capristo E, et al. Rapid suppression of alcohol withdrawal syndrome by baclofen. Am J Med. 2002; 112:226-229. [PubMed: 11893350]

98. Lyon JE, Khan RA, Gessert CE, et al. Treating alcohol withdrawal with oral baclofen: a randomized, double-blind, placebo-controlled trial. J Hosp Med. 2011; 6:469-474. [PubMed: 21990176]

99. Stallings W, Schrader S. Baclofen as prophylaxis and treatment for alcohol withdrawal: a retrospective chart review. J Okla State Med Assoc. 2007; 100:354-360. [PubMed: 18020041]

100. Addolorato G, Caputo F, Capristo E, et al. Baclofen efficacy in reducing alcohol craving and intake: a preliminary double-blind randomized controlled study. Alcohol Alcohol. 2002; 37:504508. [PubMed: 12217947]

101. Flannery BA, Garbutt JC, Cody MW, et al. Baclofen for alcohol dependence: a preliminary openlabel study. Alcohol Clin Exp Res. 2004; 28:1517-1523. [PubMed: 15597084]

102. Addolorato G, Leggio L, Agabio R, et al. Baclofen: a new drug for the treatment of alcohol dependence. Int J Clin Pract. 2006; 60:1003-1008. [PubMed: 16893442] 
103. Addolorato G, Leggio L, Ferrulli A, et al. Effectiveness and safety of baclofen for maintenance of alcohol abstinence in alcohol-dependent patients with liver cirrhosis: randomised, double-blind controlled study. Lancet. 2007; 370:1915-1922. [PubMed: 18068515]

104. Addolorato G, Mirijello A, Leggio L, et al. Management of alcohol dependence in patients with liver disease. CNS Drugs. 2013; 27:287-299. [PubMed: 23456576]

105. McLean MJ, Morrell MJ, Willmore LJ, et al. Safety and tolerability of gabapentin as adjunctive therapy in a large, multicenter study. Epilepsia. 1999; 40:965-972. [PubMed: 10403221]

106. Myrick H, Malcolm R, Brady KT. Gabapentin treatment of alcohol withdrawal. Am J Psychiatry. 1998; 155:1632. [PubMed: 9812141]

107. Bozikas V, Petrikis P, Gamvrula K, et al. Treatment of alcohol withdrawal with gabapentin. Prog Neuropsychopharmacol Biol Psychiatry. 2002; 26:197-199. [PubMed: 11853112]

108. Voris J, Smith NL, Rao SM, et al. Gabapentin for the treatment of ethanol withdrawal. Subst Abus. 2003; 24:129-132. [PubMed: 12766380]

109. Rustembegovic A, Sofic E, Tahirović I, et al. A study of gabapentin in the treatment of tonicclonic seizures of alcohol withdrawal syndrome. Med Arh. 2004; 58:5-6. [PubMed: 15017894]

110. Mariani JJ, Rosenthal RN, Tross S, et al. A randomized, open-label, controlled trial of gabapentin and phenobarbital in the treatment of alcohol withdrawal. Am J Addict. 2006; 15:76-84. [PubMed: 16449096]

111. Bonnet U, Banger M, Leweke FM, et al. Treatment of acute alcohol withdrawal with gabapentin: results from a controlled two-center trial. J Clin Psychopharmacol. 2003; 23:514-519. [PubMed: 14520131]

112. Malcolm R, Myrick LH, Veatch LM, et al. Self-reported sleep, sleepiness, and repeated alcohol withdrawals: a randomized, double blind, controlled comparison of lorazepam vs gabapentin. $\mathbf{J}$ Clin Sleep Med. 2007; 3:24-32. [PubMed: 17557449]

113. De Sousa A. The role of topiramate and other anticonvulsants in the treatment of alcohol dependence: a clinical review. CNS Neurol Disord Drug Targets. 2010; 9:45-49. [PubMed: 20201814]

114. Müller CA, Geisel O, Banas R, et al. Current pharmacological treatment approaches for alcohol dependence. Expert Opin Pharmacother. 2014; 15:471-481. [PubMed: 24456374]

115. Mason BJ, Quello S, Goodell V, et al. Gabapentin treatment for alcohol dependence: a randomized clinical trial. JAMA Intern Med. 2014; 174:70-77. [PubMed: 24190578]

116. Johnson BA. Recent advances in the development of treatments for alcohol and cocaine dependence: focus on topiramate and other modulators of GABA or glutamate function. CNS Drugs. 2005; 19:873-896. [PubMed: 16185095]

117. Rustembegovic A, Sofic E, Kroyer G. A pilot study of Topiramate (Topamax) in the treatment of tonic-clonic seizures of alcohol withdrawal syndromes. Med Arh. 2002; 56:211-212. [PubMed: 12518536]

118. Choi EA, Ki SW, Kim SE, et al. The efficacy and safety of topiramate in the treatment of alcohol withdrawal. J Korean Neuropsychiatr Assoc. 2005; 44:328-333.

119. Krupitsky EM, Rudenko AA, Burakov AM, et al. Antiglutamatergic strategies for ethanol detoxification: comparison with placebo and diazepam. Alcohol Clin Exp Res. 2007; 31:604611. [PubMed: 17374039]

120. Johnson BA, Ait-Daoud N, Bowden CL, et al. Oral topiramate for treatment of alcohol dependence: a randomised controlled trial. Lancet. 2003; 361:1677-1685. [PubMed: 12767733]

121. Johnson BA, Rosenthal N, Capece JA, et al. Topiramate for treating alcohol dependence: a randomized controlled trial. JAMA. 2007; 298:1641-1651. [PubMed: 17925516] 
Suspected Alcohol Withdrawal Syndrome (autonomic hyperactivity, agitation, tremor, seizures, delirium)

Assess using CIWA-Ar scale or Alcohol Withdrawal Scale
Perform blood tests (blood alcohol concentration, liver enzymes, gGT, MCV, glucose, electrolytes).

Assess CAGE and/or AUDIT
CIWA-Ar < 8: mild AWS

Outpatients setting

- general treatment

- supportive care

- pharmacological treatment not strictly indicated

- possibility to prescribe non-BZD drugs as monotherapy to treat AWS and to start alcohol relapse prevention (i.e.

carbamazepine, gabapentin, valproic acid, SMO, baclofen, topiramate)

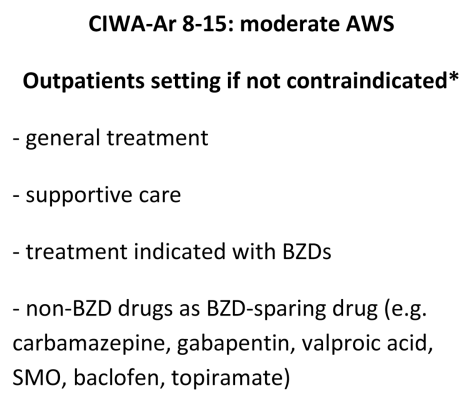

CIWA-Ar 8-15: moderate AWS

Outpatients setting if not contraindicated*

- general treatment

- supportive care

- treatment indicated with BZDs

- non-BZD drugs as BZD-sparing drug (e.g.

carbamazepine, gabapentin, valproic acid,

$\mathrm{SMO}$, baclofen, topiramate)

CIWA-Ar > 15: severe AWS

Inpatients setting

- general treatment

- supportive care

- treatment indicated with I.V. BZDs**

- barbiturates and propofol in refractory forms

- alpha2-agonists, beta-blockers, neuroleptics as adjunctive treatment for autonomic hyperactivity

*contraindication to outpatients setting: coexisting acute or chronic illness (e.g. pneumonia, liver cirrhosis), No possibility for follow-up or no contact person to monitor

the patient, pregnancy, seizure disorder or history of alcohol withdrawal seizures, suicide risk. [46]

**BZD administration schemes:

- loading dose: diazepam 10-20 mg or chlordiazepoxide 100 mg, every 1-2 hours i.v., until sedation. Then auto-tapering off. (High risk of excess of sedation: ICU rapidly available)

- symptom-triggered: diazepam 5-20 mg or chlordiazepoxide 50-100 mg or lorazepam 2-4 mg if CIWA-Ar >8-10. Assess CIWA-Ar hourly and adjust the dose (i.e. from 5 to $10 \mathrm{mg}$ of diazepam) according to symptoms severity

- fixed-dose: diazepam $10 \mathrm{mg}$ QID for 1 day, then $5 \mathrm{mg}$ QID for 2 days, then tapering off; alternatively chlordiazepoxide 50-100 mg QID for 1 day, then 25-50 mg QID for 2 days, with subsequent tapering off (to be preferred in patients at risk for severe AWS)

Abbreviations: CIWA-Ar (Clinical Institute Withdrawal Assessment for Alcohol, revised); DT (delirium tremens); ICU (Intensive Care Unit); gGT (gammaglutamyltransferase); MCV (mean corpuscular volume); BZD (benzodiazepine); AWS (Alcohol Withdrawal Syndrome); SMO (sodium oxybate), CAGE (Cut downAnnoyed-Guilty-Eye opener); AUDIT (Alcohol Use Disorders Identification Test).

Figure 1. 


\section{TABLE 1}

Signs and symptoms of alcohol withdrawal syndrome, divided per stage [60, 74].

\begin{tabular}{|l|l|l|}
\hline Stage & Time of onset after last drink & Signs and symptoms \\
\hline I - Minor Withdrawal Symptoms & $6-12 \mathrm{~h}$ & $\begin{array}{l}\text { Tremors, diaphoresis, } \\
\text { nausea/vomiting, hypertension, } \\
\text { tachycardia, hyperthermia, tachypnea }\end{array}$ \\
\hline II - Alcoholic Hallucinosis & $12-24 \mathrm{~h}$ & $\begin{array}{l}\text { Dysperceptions: Visual (zoopsy), } \\
\text { auditory (voices) and tactile } \\
\text { (paresthesia) }\end{array}$ \\
\hline III - Alcohol Withdrawal seizures & $24-48 \mathrm{~h}$ & $\begin{array}{l}\text { Generalized tonic-clonic seizures (with } \\
\text { short or no postictal period) }\end{array}$ \\
\hline IV - Delirium Tremens & $48-72 \mathrm{~h}$ & $\begin{array}{l}\text { delirium, psychosis, hallucinations, } \\
\text { hyperthermia, malignant } \\
\text { hypertension, seizures and coma }\end{array}$ \\
\hline
\end{tabular}

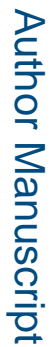

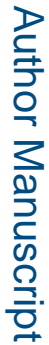


TABLE 2

Clinical Institute Withdrawal Assessment for Alcohol - revised (CIWA-Ar) scale [36].

\begin{tabular}{|l|l|}
\hline Clinical Institute Withdrawal Assessment for Alcohol revised \\
\hline Symptoms & Range of scores \\
\hline Nausea or vomiting & 0 (no nausea, no vomiting) -7 (constant nausea and/or vomiting) \\
\hline Tremor & 0 (no tremor) -7 (severe tremors, even with arms not extended) \\
\hline Paroxysmal sweats & 0 (no sweat visible) -7 (drenching sweats) \\
\hline Anxiety & 0 (no anxiety, at ease) -7 (acute panic states) \\
\hline Agitation & 0 (normal activity) -7 (constantly trashes about) \\
\hline Tactile disturbances & 0 (none) -7 (continuous hallucinations) \\
\hline Auditory disturbances & 0 (not present) -7 (continuous hallucinations) \\
\hline Visual disturbances & 0 (not present) -7 (continuous hallucinations) \\
\hline Headache & 0 (not present) -7 (extremely severe) \\
\hline Orientation/clouding of sensorium & $\begin{array}{l}0 \text { (orientated, can do serial additions) }-4 \text { (Disorientated for place } \\
\text { and/or person) }\end{array}$ \\
\hline
\end{tabular}

Modified from: Sullivan JT, Sykora K, Schneiderman J, Naranjo CA, Sellers EM. Assessment of alcohol withdrawal: the revised Clinical Institute Withdrawal Assessment for Alcohol Scale (CIWA-Ar). Br J Addict 1989;84:1353-7. 
TABLE 3

Risk factors for severe alcohol withdrawal syndrome (CNS: central nervous system; BAL: breathe/blood alcohol concentration; CIWA-Ar: Clinical Institute Withdrawal Assessment for Alcoholism, revised; AST: aspartate aminotransferase) [42, 60].

\begin{tabular}{|l|}
\hline Previous episodes of alcohol withdrawal (detoxification, rehabilitation, seizures, delirium tremens \\
\hline Concomitant use of CNS-depressant agents, such as benzodiazepine or barbiturates \\
\hline Concomitant use of other illicit substances \\
\hline High blood alcohol level (BAL) on admission (i.e. $>200 \mathrm{mg} / \mathrm{dl}$ ) \\
\hline $\begin{array}{l}\text { Evidence of increased autonomic activity (i.e. systolic blood pressure }>150 \mathrm{mmHg} \text {, body temperature }> \\
\left.38^{\circ} \mathrm{C}\right)\end{array}$ \\
\hline Older age \\
\hline Moderate to severe alcohol withdrawal at diagnosis (CIWA-Ar $>10)$ \\
\hline $\begin{array}{l}\text { Medical or surgical illness (i.e. trauma, infection, liver disease, CNS infection, electrolyte } \\
\text { disturbances, hypoglycaemia, etc.) }\end{array}$ \\
\hline Severe alcohol dependence \\
\hline Abnormal liver function (elevated AST) \\
\hline Recent alcohol intoxication \\
\hline Male sex \\
\hline
\end{tabular}




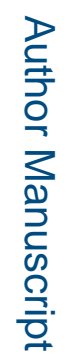

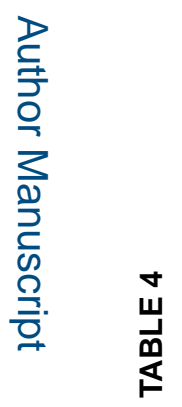

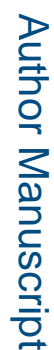

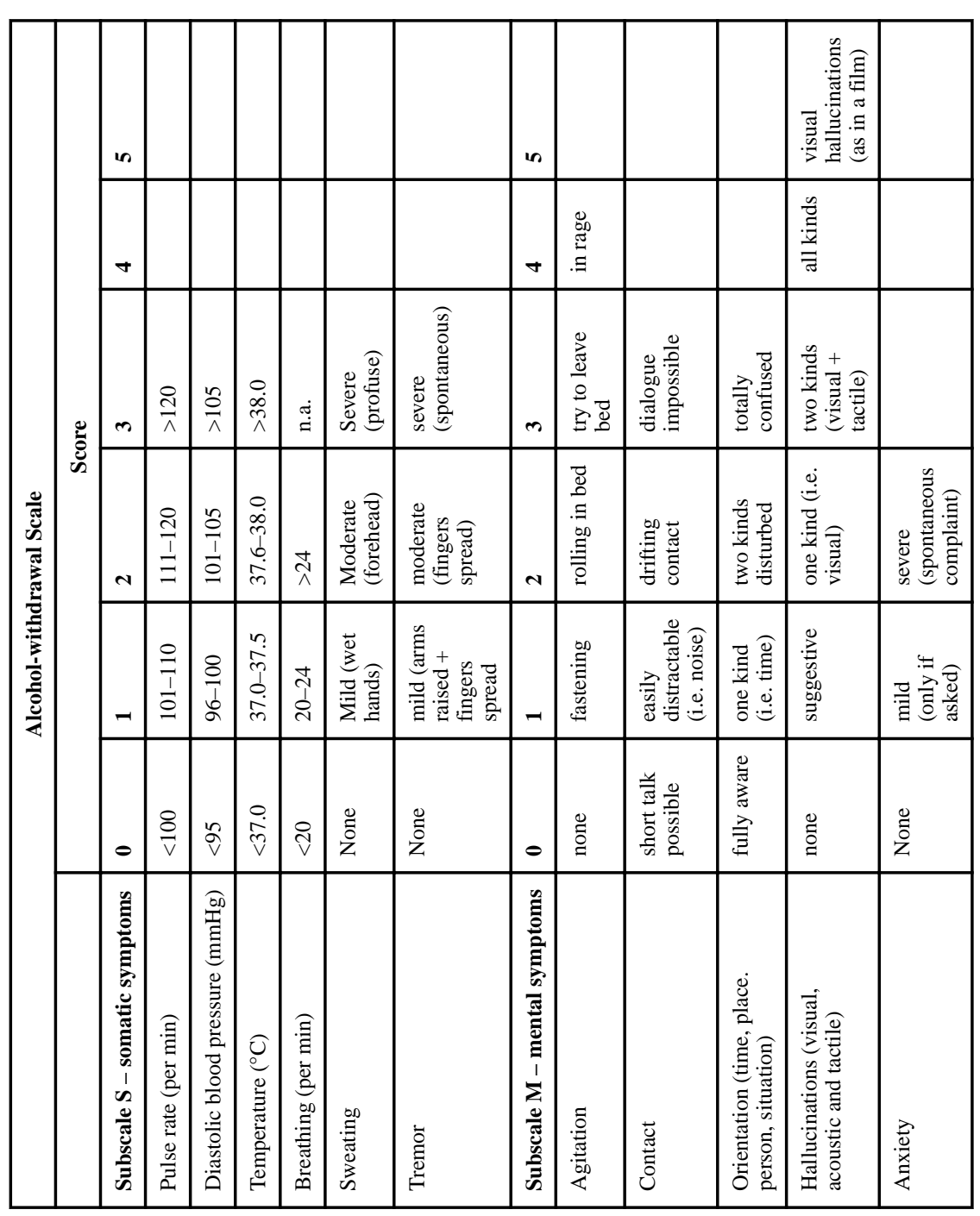

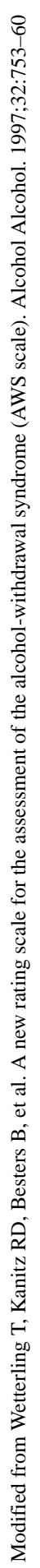

Drugs. Author manuscript; available in PMC 2016 August 09. 
Table 5

Pharmacokinetic characteristics of different benzodiazepines used to treat alcohol withdrawal syndrome [21, $54,61]$

\begin{tabular}{|l|l|l|l|l|}
\hline DRUG & HALF-LIFE & $\begin{array}{l}\text { ACTIVE } \\
\text { METABOLITES }\end{array}$ & METABOLISM & EXCRETION \\
\hline Diazepam & $\begin{array}{l}20-80 \mathrm{~h} \\
(\text { metabolites 30- } \\
100 \mathrm{~h})\end{array}$ & Yes & Hepatic & $\begin{array}{l}\text { Hepatic - urinary } \\
\text { (metabolites) }\end{array}$ \\
\hline Chlordiazepoxide & $\begin{array}{l}5-30 \mathrm{~h} \\
\text { (metabolites 30- } \\
200 \mathrm{~h})\end{array}$ & Yes & Hepatic & $\begin{array}{l}\text { Hepatic - urinary } \\
\text { (metabolites) }\end{array}$ \\
\hline Lorazepam & $10-20$ & No & Hepatic & Urinary, fecal \\
\hline Oxazepam & $10-20$ & No & Hepatic & Urinary \\
\hline Midazolam & $2-6$ & Yes & Hepatic, Gut & Urinary \\
\hline
\end{tabular}

(1)

을 